[Alcorn, N. (2008). Evidence and Education: The Braided Roles of Research, Policy and Practice in New Zealand. New Zealand Annual Review of Education, 17, 5-23]

\section{Evidence and Education: The Braided Roles of Research, Policy and Practice in New Zealand}

\author{
NOELINE ALCORN
}

\section{Abstract:}

Calls for educational policy and practice to be evidence-based have become insistent, yet there is ongoing contestation of the purpose and value of educational research. This paper addresses criticism of research from practitioners, politicians and policy makers and from within the research community itself. It examines the impact of the PBRF in New Zealand and the call for evidence-based practice here, in the UK and the US. It draws attention to research studies that are possible models for a principled and methodologically inclusive way forward and develops a set of principles for guiding future development in teacher education and educational research.

Peacher Education in New Zealand, for more than a century the preserve of independent stand-alone teachers colleges, is now, following recent mergers, largely university based. Successful mergers require both college and university staff to forge new professional identities and relationships, and a key area for fruitful collaboration is research. A major challenge for all education faculties is to determine what research issues and questions they will prioritise in the new environment, and how their work will critique but also underpin ongoing reform of our educational policy and practice at institutional and national levels. At the same time, all New Zealand academics face new accountability imperatives through the Performance Based Research Fund (PBRF) and calls for evidence-based practice.

For teacher educators in New Zealand, pressure to perform as researchers is comparatively new. Until 1990 there existed a clear

\section{Noeline Alcorn}

distinction between research-based university departments and more practice-related teacher education institutions, closely linked to the wider teaching profession. Like most binary distinctions, this one is flawed, but before 1990 college staff were mainly recruited from the profession on the basis of their expertise in teaching and were not required to conduct research. On the other hand, university staff, who were expected to engage in research, were not required to engage with schools in the process, though some did so and a number were involved in teacher education programmes.

In this paper I examine the implications of the new research context in a wider framework with a view to identifying principles for ongoing practice. The paper first addresses scepticism about, and criticism of, educational research from practitioners, politicians and policy makers, and from within the research community itself. It examines the impact of the PBRF in New Zealand and explores the wider call for evidence-based practice here, in the United Kingdom and the United States. It then draws attention to research studies that provide possible models for a principled and methodologically inclusive way forward, before enunciating a possible set of principles for guiding future development in teacher education and educational research.

\section{Attacks on Educational Research}

Educational research struggles to command the respect accorded to some other disciplines. John Furlong's presidential address to the British Educational Research Association (BERA) in 2003 claimed that "as a research community I believe that we are still troubled by our reputation for poor quality work and by the accusation that we have little impact on policy and practice" (Furlong, 2004, p. 344). Practitioners and policy makers often characterise educational research as woolly or irrelevant. They are often disappointed that research studies do not provide a firm basis for policy intervention or for classroom practice. We need to ask why. One answer is that because learning is contextually based, it is impossible for educational research about learning to come up with firm answers to troubling questions that will work in any situation. In addition, much educational research is small scale and nongeneralisable while the field is often bedevilled by internal wars over methodology and purpose.

Ellen Condliffe Lagemann, in her scholarly study of educational research in the United States, An Elusive Science: The Troubling History of Education Research, asks why "has this domain of scholarly work always 
been regarded as something of a stepchild, reluctantly tolerated at the margins of academe and rarely trusted by policy makers, practitioners or the public at large" (Lagemann, 2000, p.x). She had earlier suggested (Lagemann, 1989) that the trouble with educational research is that Dewey lost and Thorndike won. By the beginning of the twentieth century, educational study had moved out of the school and ongoing collaboration with practitioners and into the laboratory where accurate measurement could take place. Those who fostered the shift, she believes, did so in a genuine attempt to enhance the status of educational research and increase its scientific validity.

Eager to elevate school leaders to the place of respect and independence they believed they deserved, early educationalists tried to emulate their brethren in the "hard" sciences (or at least the developed social sciences) and failed to realise that their goals might have been better served by instead pondering what distinctive characteristics might comprise rigor and relevance in this particular domain of scholarship. (Lagemann, 2000, p. xii)

Lagemann notes that, in his relatively brief tenure at the experimental Chicago laboratory school, Dewey posited a number of important tenets: that educational study, to be experimental, had to be conducted in a school; that it should both advance and link scientific and social innovation; that it should aim to create an educational system in which teaching and learning would be much wider than narrowly defined school functions; and that educational enquiry should involve teachers and parents as well as university researchers. In contrast, Thorndike and colleagues, in an effort to "professionalise" teaching, followed a narrower behaviourist and determinist view, believing that it was not possible for education to lessen differences between groups and that improvement could come only from scientific (psychological) knowledge developed outside schools, uncontaminated by particular teachers or children. The most important study for graduate students was not philosophy but statistics. "Thorndike urged his students not to waste their time in school visits except to administer some test or experimental device" and predicted that, as educational psychology garnered more and more knowledge, "it would tell the effect of every possible stimulus and the cause of every possible response in every possible human being" (Lagemann, 2000, p. 59). Surveys came to dominate educational research and the psychologists increasingly saw teachers as technicians. Measurement reigned supreme for a long period. It is interesting that the August American Educational Research Association (AERA), established in 1915, grew out of the meetings of a group committed to "the use of educational measurement in all educational research" (p. 94).

Lagemann claims that during most of the twentieth century educational researchers in the US often lacked a sense of social purpose, and rarely engaged with thinkers in other disciplines, such as anthropology, that could have made an important contribution to the development of alternative methodologies. She is heartened by recent developments such as the rise of qualitative methodologies, the recognition of the importance of culture in the classroom, the application of the findings of cognitive science in the classroom, and the attempts of scholars to find new ways to communicate and collaborate with those they hoped to influence (p. 212).

From the 1960s, especially in the United Kingdom, sociology became a major counter force to the measurement influence on educational research, with issues such as class, gender and ethnicity foregrounded. There was often optimism about its impact. Yet from the 1970s, successive governments attacked educational researchers and teacher educators for a left wing stance and woolly liberalism. A significant insider critique came from David Hargreaves in an invited lecture to the Teacher Training Agency (TTA) (Hargreaves, 1996). He argued that educational research should have more relevance for, and impact on, the professional practice of teachers by generating a better body of knowledge for teachers to draw on. Recent international emphasis on research that makes a difference to classroom practice has focussed attention on the role of the teacher. While this may be a welcome change from the "teacher bashing" of the early 1990s, it carries with it the danger that issues impacting on learning from outside the classroom will receive less emphasis, and that teachers will be held responsible for all instances of failure to learn.

Allan Luke, a distinguished researcher, who has also served as a senior bureaucrat in Australia, has attempted to shift the focus of the debate. He contends:

governments and systems, in many cases for the first time, and with no small amount of trepidation, are reaching out to the educational research community for substantive analyses, for policy formation, for ideas about how to remake the connections between curriculum, communications media old and new, and everyday classroom practice. (Luke, 2003, p. 90) 
For Luke, big picture issues are crucial: the impact of poverty on children starting school; the urgent need to build new forms of pedagogic practice and action in the middle years of schooling to change the educational performance of those alienated from formal education; and the imperative to find new pathways in secondary education to prepare students for the complexity and diversity of society in the early 21st century.

\section{Research Assessment in New Zealand: the PBRF}

The policy context for academic educational research in New Zealand shifted radically with the implementation of the Performance Based Research Fund (PBRF) assessment in 2003. Like England, New Zealand is immersed in an audit and accountability culture, one in which, as Onora O'Neill claimed in her 2002 Reith lectures, there is a climate of distrust of professionals (O'Neill, 2002). For the tertiary education sector, the clearest indication of this audit culture is the establishment of the PBRF process, which measures the research performance of all academics teaching in degree level programmes and assigns individual grades to each. For individuals and institutions the PBRF is a high stakes exercise since it determines the allocation of research funding in the tertiary sector.

For the field of education the first assessment results were highly problematic. While there was considerable strength at the top end of the scale, there was also a large tail. This was demoralizing for individual academics and for the field. Staff whose professional esteem had been built on practical and professional expertise in teaching were suddenly rated on the quality and quantity of their research. The transition from teacher to researcher would be easier if teachers saw their new research role as enabling them to work more effectively with students or develop greater professional understanding.

The PBRF puts pressure on academics and their institutions to perform in ways measured by the assessment process. Institutions are concerned to maximize their research standings and status and the financial rewards attached to high quality ratings. In England, universities have engaged in poaching wars to attract top research "performers" (Boston, 2006). Some departments with modest scores are under threat or have been disestablished. The consequences of failure are significant. For example, after the last Research Assessment Exercise only 31 departments of education in the UK were rated $5^{*}, 5$ or 4 and thus received core funding to support their research. A further 41 departments rated $3 a$ or $3 b$ lost their research funding.
The PBRF may also, probably unintentionally, cause certain types of research to be privileged. The timeframes will tend to favour smaller projects, especially in the second half of each cycle. Longitudinal studies and research books may become rarer. There could be a temptation to publish before findings have been fully considered. There could be a plethora of new journals competing for recognition as "top quality". While the PBRF definition of research is a broad one, catholic as to methodologies, there is an expectation of quantity as well as quality. In contrast, Northrop Frye, one of Canada's most prestigious literary scholars, productive well into his 80 s, wrote in later life that he would never have achieved tenure in a modern university. His first book took seven years to produce and his second 13. Yet both are seminal works.

The PBRF model privileges the perception that research is a specialized activity carried out in tertiary institutions, with published findings assessed by peers. Published research is judged on the company it keeps. The standing of journals becomes important and often international outlets are preferred. The research imperatives of the PBRF mean that staff in professional schools such as education face a new apprenticeship in joining the university staff, often in mid-career. They must undertake advanced degree studies to be initiated into research processes by other academics, learn to think critically about methodologies, epistemologies and the reliability of evidence. Many new academics have found, however, that engaging in research can be inherently rewarding and exciting when motivated by qualities that also sustain teaching: intellectual curiosity, a desire to solve pressing problems, or to improve practice and help others. At the same time there are other pressures for education academics to pursue research, coming from international trends towards evidence-based practice.

\section{Evidence-Based Practice}

While promoting evidence-based practice in education is currentlya key aim of the Ministry of Education, the concept has a longer and problematic recent history in the United States and the United Kingdom. In one sense we can trace it back to Dewey's laboratory school in Chicago, but its recent manifestation in America bears little resemblance to that heritage. While the notion itself sounds relatively benign, definitions of what counts as evidence and how it can be incorporated into educational policy and practice are hotly contested. As Hammersley (2004) has noted, "its name is a slogan whose rhetorical effect is to discredit opposition" (p. 143). 
One driver of evidence-based practice is national competitiveness fuelled by international surveys of student achievement. Another, ironically, is the recognition that schooling often perpetuates social disadvantage. In the United States the issue of educational disparities was highlighted through the publication of Coleman's (1966) findings that minority students scored "considerably lower" on achievement tests and that the disparity increased with years of schooling (Lagemann, 2000 , p. 196). Federal and state level programmes designed to address this disparity were implemented. Politicians then professed puzzlement and anger about the lack of precise information about the effect of reform initiatives and "what works" and looked for people to blame, such as teacher educators and the universities.

As a result there has been a call for narrowing the scope of research, accepting only the "gold standard" of randomly controlled trials. For example, Slavin (2003) claimed that "far more testing goes into our students' hair gel and acne cream than into most of the curriculums or instructional methods teachers use" ( p. 12). He believes rigorous evaluation in which children and schools are randomly assigned to experimental and control groups is the only way forward and "could finally bring education to the point reached early in the 20th century by medicine, agriculture and technology, fields in which evidence is the lifeblood of progress" (p. 16). The demand for evidence-based practice has impacted directly on teacher education.

In the United Kingdom, David Hargreaves' TTA lecture was the catalyst for robust debate, attacks on and defence of educational research (Tooley, 1998; Woodhead, 1998; Evans \& Benefield, 2001; Hammersely, 2001; Eliot, 2001; Oakley 2001; Hodkinson, 2004). Hargreaves drew attention to the work of the Cochrane Centre at Oxford, which reviewed best practice studies in medicine and suggested that education might adopt such a model, particularly as education and medicine were both people-centred professions where practitioners make sophisticated judgments in a highly skilled manner in dealing with individual patients or learners. Hargreaves insisted that practitioners in both fields are "pragmatic professionals, primarily interested in what works in what circumstances and only secondarily in why it works" (1997, p. 408). He rated much educational research as "poor value for money in terms of improving the quality of education provided in schools". Chris Woodhead, then head of the Office for Standards in Education (Ofsted) attracted media attention for assessing recent educational research as dross (Woodhead, 1998). Yet in 2000,
Secretary of State for Education and Employment, David Blunkett, expressed the government's commitment

to be guided not by dogma but by an open-minded approach to understanding what works and why. This is central to our agenda for modernizing government: using information and knowledge much more effectively at the heart of policymaking and policy delivery (Blunkett, 2000, p.2)

One outcome of the British government's pressure for more "scientific" evaluation of educational practice was the establishment of the Evidence for Policy and Practice Information and Coordinating Centre (EPPI). Under the directorship of Anne Oakley, the Centre has carried out a number of research reviews but its methodology has been attacked for its restrictiveness and prescription (Hammersley, 2001, 2004; Andrews, 2004; MacLure, 2005). Completed reviews, which began by identifying many studies, rejected most of them for lack of specific focus or rigour. For example, an investigation into effective literacy teaching in the 4 to 14 age range of mainstream schooling identified 1265 initial hits but only two were considered for final review (MacLure, 2005, p. 401). There are fears that authorities may seize on results of these selected studies and prescribe practice, thus eroding the professional judgment and agency of practitioners. Hargreaves tried to counter this fear by suggesting that practice should be "research informed" rather than "research based" and by acknowledging that practical decisions are inevitably context bound (Hargreaves, 1997).

Others have pointed out that evidence-based practice in medicine is subject to many of the same problems as education: doctors are often unwilling and/or lack time to gain sophistication in using original literature or merely unwilling to change (Peile, 2004). After all, if they engaged in evidence-based practice, all doctors would be non-smokers, exercising regularly.

Pring (2004) in summarizing the debate writes:

Given the range of possible discourses about education, then the danger lies in the imperialism of any one form of discourse, together with its distinctive notion of evidence. Two false consequences are frequently drawn from this.... On the one hand, a narrow and thus too demanding a notion of evidence is adopted, thereby excluding, as irrelevant or as not rigorous or as arbitrary, deliberations about educational policy and practice. On the other hand, in recognizing the distinctively practical, context-bound and value-laden nature of 
educational deliberations, many will reject completely the large-scale experimental search for evidence. Thus is created the false dualism between the quantitative and qualitative approaches to research, which has caused so much more damage (pp. 211-2).

In New Zealand, the Ministry of Education has commissioned and published a number of Best Evidence Syntheses (Alton-Lee, 2003; Biddulph, Biddulph \& Biddulph, 2003; Farquhar, 2003; Mitchell \& Cubey, 2003). Like the reports of the EPPI centre, these reports sought to sift the best evidence available, seeking robustness, size and empirical evidence. These studies, however, are far less restrictive than their English counterparts and provide a highly valuable contribution to the literature. The Ministry, in conjunction with the Teachers Council, has also commissioned four reports on teacher education, claiming that there is little published evidence of "what works" in initial teacher education or later development. This stance rejects much New Zealand research as local, small scale and fragmented-all charges that were laid against the research community in England and the United States.

Evidence-based, evidence-informed or evidence-engaged practice is now becoming an accepted part of educational rhetoric in New Zealand though the focus here has been less on university research and more on encouraging teachers to gather and use data to drive their practice. The Education Review Office (ERO) in its 2005 Annual Report noted that in 2006 it would conduct a national evaluation of how effectively schools collect and use student achievement information and data to improve the achievement of students (Education Review Office, 2005).

Teachers are exhorted to form professional learning communities to examine systematically evidence about learning in their classrooms and schools and plan together for improvement. Professional learning communities are not a new idea. They sprang up all over New Zealand following the New Education Fellowship conference in 1937 as teachers excitedly discussed the ideas presented by international visitors such as Susan Isaacs and Harold Rugg. Another variant was the Quality Teaching Circles concept, advocated as a professional development tool by Stewart in the 1980s (Stewart, 1980). The key difference in the 2000s seems to be the weight placed on gathering and interrogating children's achievement data and seeking ways to raise their attainment (Hattie, 2005; Timperley \& Parr, 2005). Much emphasis is placed on New Zealand's standing in international surveys such as the OECD-initiated Programme for International Student Assessment (PISA) and the Progress in International Reading Literacy Study (PIRLS) which indicate that intra-school variation is excessive and that while top New Zealand students score highly in key areas, the low scores of those in the lowest quartile are disturbing in a country that prides itself on opportunity for all. The Picking up the Pace project (Phillips, McNaughton \& McDonald, 2001) demonstrated that when teachers in low decile schools are offered targeted professional development and support, including a greater range of strategies for teaching literacy in junior classrooms, student achievement can match that of the average for their age group. However, there is a big step between this finding and encouraging other teachers to emulate these results without the support. There is also danger that teachers can be expected to level the playing field in spite of the unevenness of the terrain on which it sits.

If education academics are to engage with teachers in generating practice-based evidence to underpin evidence-based practice and avoid the narrowness of what has occurred in Britain and the United States, then there needs to be considerable debate about what counts as evidence, what weight can be given to teachers' tacit understanding or practice narratives, to the findings of small scale local action research projects and to the dissemination of findings from large scale New Zealand and international studies. It is important that transparency does not lead to a mechanistic approach that negates the findings from small samples or qualitative methodologies. The government's Teaching and Learning Research Initiative (TLRI) to fund studies involving collaboration between teachers and tertiary researchers is an important step forward in fostering a genuine climate of enquiry, developing links between academics and teachers, and building capacity to interrogate and interpret a variety of evidence.

Above all, New Zealand needs to avoid the twin dangers of mandating narrow evidence-based practice as the "one best way" and so attempting to prescribe professional enquiry and ascribing causality to findings prematurely.

What Can A New Zealand School of Education Within A University Do?

The University of Waikato School of Education can be used as a case study in developing a research programme in the current New Zealand climate. In its decade of experience in trying to develop a research culture and work towards a definition of university-based teacher education practice it has experienced failures and successes.

Early on, the School adopted a vision statement that it would try to extend knowledge and improve practice in education. The statement 
integrates teaching and research and recognizes that tertiary education lecturers are teachers as well as researchers. It acknowledges that education is much wider than schooling and must be informed by knowledge of the past, by understanding of social and cultural contexts and by philosophical underpinnings as well as by investigations of current practice and understanding of cognitive and learning processes. But part of the task in developing evidence-based practice is to ensure that much research rests on practice-based evidence.

The School worked to a strategic plan. It took deliberate decisions to make senior appointments in significant fields that fitted with its core values: several new chairs were established, most notably in teacher education, Māori education and literacy education. It set up the Wilf Malcolm Institute for Educational Research as an incubator and catalyst to provide infrastructural support for research.

Three Waikato studies have potential as working models. They are all longer-term projects that have attracted national and international attention. They provide data and findings for evidence-based practice at the university and in the education sector more widely, and they are based on working closely with teachers and learners as well as with the Ministry of Education as a funding agent and major audience.

\section{Development and implementation of the Technology curriculum}

The first project is the research by Professor Alister Jones and colleagues that preceded and followed the development and implementation of the New Zealand Technology curriculum. Ten years on it is perhaps difficult to remember how radical was the shift from gendered technical subjects, such as cooking and woodwork, introduced at intermediate school level, to our current notion of technology as a discipline which, like literacy, permeates a number of other curriculum areas. Its development, championed by Minister of Education, Dr Lockwood Smith, was challenged by many teachers whose livelihood depended on the continuation of the status quo or who queried the legitimacy of the new field.

To establish a sound conceptual base for the new subject, the research was of necessity multi-dimensional, comprising both a meta-analysis of key articles and sustained classroom research on teacher beliefs and practices. After the curriculum was developed and introduced, the team carried out case studies over a three-year period. When the classroom research indicated that changes in perceptions and developing concepts were fragile and that teachers were puzzled about what the subject was and how to teach it, further research underpinned professional development based on a planning framework encompassing conceptual, procedural, societal and technical goals.

Reflecting on the decade-long involvement, Jones (2005) suggests that, as the project was about exploring ways to enhance learning, its success depended on collaborative relationships and shared ownership of problems, mutual respect, and the longitudinal nature of the project, which gave schools and teachers time to reflect on new ideas and adapt to new challenges.

\section{Te Kotahitanga}

Professor Russell Bishop's aim on taking up his foundation chair in Māori Education was to address disparities in educational achievement between Māori and pakeha students and to retain Māori students in school. Starting from a theoretical base developed in his book Culture Counts (Bishop \& Glynn, 2003) he set out to discover what views and expectations Māori learners in years 9 and 10 had of their schooling, what worked for them in the classroom and what did not. He recorded their stories, and those of their parents and teachers. From these narratives emerged a model of effective teaching for Māori students consistent with Māori cultural values, which concentrated on building relationships between teachers and students and allowed students to bring their knowledge and cultural identity into the classroom. The students' stories were fed back to groups of teachers whose analysis led them to confront their own discursive positioning: instead of blaming students or structures for student lack of achievement, these teachers determined to change their own attitudes and practice. As they implemented the new ways of working, their teaching was supported by facilitators, while the attendance, engagement and achievement of the students was monitored by the research team. For schools involved in the project, progress has not always been easy, but the gains in student attitude and achievement have been clearly evident. Quantitative analysis of the observational data has determined that classroom interactions have changed from being 80 percent teacherdominated to a balanced 50/50 teacher/student initiated.

\section{Learning Stories in Early Childhood Education}

Professor Margaret Carr has had a major influence on the way policymakers and practitioners think about curriculum, learning dispositions and assessment in New Zealand early childhood education. 
Her interest in assessment grew out of her rejection of assumptions she had held as an early childhood teacher, and her growing conviction that assessment should enhance learning and foreground credit rather than deficit. So she asked

- How can we describe early childhood outcomes in ways that make valuable statements about learning and progress?

- How can we assess early childhood outcomes in ways that promote and protect learning?

She was aware that many committed early childhood educators resisted assessment, believing it involved standing in judgment and took them away from working and being with children. A further research question emerged:

- How were educators assisted to shift from a folk model of assessment to an alternative model?

She described the differing perspectives of those in the project.

I was interested in a set of problematic assumptions: the practitioners I worked with were especially interested in practice; they asked questions like "How can we help Joseph on Monday?" It has been a journey that a number of educators and I have undertaken together.

That journey is still in progress. (Carr, 2001, p.175)

The research on learning stories was based on detailed observation of children's activities and taping of their conversations in a variety of early childhood settings, as well as the perceptions of their teachers and parents. Carr's analysis was also informed by her deep understanding of the psychological and sociological contexts for children's learning. The developing theory was tested through evolving practices within the early childhood settings in which the research team worked.

While these three projects are ostensibly very different from each other, taken together they form the basis for analysing the principles and conditions needed for implementing successful practice-based research which makes a difference to learning.

- Each of the projects was long term. The Ministry of Education recognized the need for ongoing funding both for the research and for skilled facilitation of the resulting professional development.

- Each project treated practitioners and students as important colleagues who shared in the generation and interpretation of data. They eschewed the model of a researcher passing on findings for practitioners to adopt.
- All the research leaders insisted that their findings and theories must be workable in practice as well as being theoretically sound.

- Each project enabled colleagues new to research to develop skills as they were mentored through the process and developed new research methodologies.

- The theoretical backgrounds and initial methodologies were very different but presenting evidence for teachers to reflect, make meaning from and work with was crucial to them all.

\section{What Principles Should Guide Future Development?}

The educational research community in Aotearoa New Zealand and internationally needs to develop a sense of confidence that its work is vital to the understanding and ongoing improvement of education. As well as critique, research must engage with the real problems of the day. In order to do so, researchers need to move beyond the binaries of positivism and progressivism.

Research may not have been a major emphasis for teacher educators until recently but the world has changed. Teacher educators and other education academics need to develop new professional learning communities of enquiry, to work with teachers and, where appropriate, with Crown Agencies and parents. They need to challenge each other, to be aware of their history as well as where they want to go, but avoid narrow and sometimes sterile methodological wars that can work against the very goals they seek to achieve. And they need to remember that developing a pervasive research culture takes time.

Education researchers need to be clear about the purposes and underlying assumptions of their projects and where they fit in a wider policy and practice agenda. For example, Cochran-Smith and Fries (2005) claim that research on teacher education in the US has moved through three phases since the 1950s: first it was construed as a training problem needing carefully designed competency based programmes; from the 1980s it was characterised as a learning problem and researchers of different persuasions sought to define a knowledge base for competent teaching professionals; from the mid 1990s it has become a policy problem where the onus on researchers is to demonstrate how teacher education practice can be seen to be both successful and cost effective. There are whiffs of this latest agenda in New Zealand. There is a need to be wary about approaches that favour research which is empirical and statistical and which place little emphasis on context or 
culture. Even the current international emphasis on student achievement needs to be questioned, as much for what is left out as what is emphasised. For instance, teachers could raise the reading performance of students but ignore their appreciation of fantasy, imaginative response to texts or kinaesthetic sense. They could pursue numeracy strategies but ignore spatial relationships in mathematics.

Researchers need to nurture their own imagination and intuition. Just as children's imagination is developed through play and the arts, as well as more traditional classroom activities, so researchers need time for day-dreaming and wondering. New discoveries are seldom made because researchers have been examining and interpreting evidence, especially numerical data. Often the trigger is a feeling that what they are doing is not working and that theory may give us a better way. Margaret Carr's rejection of the assessment assumptions she had acted on is such an example. A leap of imagination is sometimes needed.

Researchers need to be aware that research is likely to generate further questions rather than find answers, and that all answers are interim ones. C. E. Beeby enunciated this in his early writing on the work of the New Zealand Council for Educational Research (NZCER) (Beeby, 1935). When his words were quoted at the opening of the Wilf Malcolm Research Institute, the Minister of Education half jokingly noted that he needed answers not questions. But Beeby was surely right. A culture of enquiry by its very nature means that we continue to find new questions to ask as we build on or challenge our accepted assumptions or practices. For example, Cochran Smith and Lytle (1993, p. 55) describe teacher enquiry as a "shift from problem solving to problem posing, from quick closure to deeper exploration and from making judgments to discovering relationships based on data."

While rigour is needed in research, so also is breadth and generosity. Researchers need to guard against narrow definitions of good research methodology and learn to engage constructively as well as critically with the work of others. Research methods should be relevant to the research questions, and most complex research requires mixed methods. New Zealand has few examples of competing ideologies claiming research superiority though, as a number of scholars have pointed out, we have suffered from dominant discourses that could be construed as anti-education. However, the United States provides a number of cautionary tales in which proponents of very different agendas interpret evidence in radically different ways. For example, Cochran-Smith and Fries note: each of the multiple agendas for the reform of teacher education that emerged and sometimes collided during the mid 1990s and into the 2000 s claimed to have an empirical base. Numerous opposing claims were presented about the "evidentiary warrant" that supported these agendas. (2005, p. 92)

The criticism of the EPPI reviews in Great Britain drew attention to a narrowing and restriction we would do well to avoid.

Alan Luke throws down the gauntlet in the conclusion to his 2002 Radford lecture. He claims that we need a new research agenda in education which avoids "causal factors" and looks at all evidence through social theoretic lenses, using models that stress mediation and contextualisation to develop new narratives, pathways and policies.

Our generational tools have been those of critique. What a powerful evidence-based educational policy needs is a rich, critical, multidisciplinary social science.... Of governments and policy makers we need to demand an educational policy that can be read and constructed as but one component of broader social policy and cultural strategy.

For such a task neither Dewey nor Thorndike, neither unreconstructed progressivism or born again positivism will suffice. A critical education project for remaking education can afford neither a purity of research - uncontaminated by normative responsibility for what is to be done - normative policy based on pseudo science and anecdote. Nor can we operate solely as insiders or outsiders in the worlds of research and policy formation. We have our work cut out for us. (Luke, 2003, p. 105)

\section{References}

Alton Lee, A. (2003). Quality teaching for diverse students in schooling: Best evidence synthesis. Wellington: Ministry of Education.

Andrews, R. (2004). Between Scylla and Charybdis: The experience of undertaking a systematic review in education. In G. Thomas \& R. Pring (Eds.), Evidence-based practice in education (pp. 65-76). Berkshire: Open University Press.

Beeby, C. E. (1935). Educational research in New Zealand. Wellington: New Zealand Council for Educational Research.

Biddulph, F., Biddulph, J., \& Biddulph, C. (2003). The complexity of community and family influences on children's achievement in New Zealand: Best evidence synthesis. Wellington: Ministry of Education. 
Bishop, R., \& Glynn, T. (2003). Culture counts: Changing power relations in education. Palmerston North: Dunmore Press.

Boston, J. (2006). Rationale for the Performance-Based Research Fund and its evaluation. In L. Bakker, J. Boston, L. Campbell, \& R. Smyth (Eds.), Evaluating the Performance-Based Research Fund: Framing the Debate (pp. 5-31). Wellington: Institute of Policy Studies, Victoria University of Wellington.

Blunkett, D. (2000). Influence or irrelevance: Can social science improve government? Speech to ESRC Council. Retrieved from BERA website.

Carr, M. (2001). Assessment in early childhood settings: Learning stories. London: Paul Chapman Publishing.

Cochran-Smith, M., \& Lytle, S. (1993). Inside outside: Teacher research and knowledge. New York: Teachers College Press.

Cochran-Smith, M., \& Fries, K. (2005). Researching teacher education in changing times: Politics and paradigms. In M. Cochran-Smith \& K. Zeichner (Eds.), Studying teacher education: The report of the AERA panel on research and teacher education (pp. 69-110). Washington \& New Jersey: AERA/Lawrence Erlbaum Associates.

Codd, J. (1999). Educational reform, accountability and the culture of distrust. New Zealand Journal of Educational Studies, 34(1), 45-53.

Coleman, J. (1966). Equality of educational opportunity. Washington: US Department of Health, Education \& Welfare, Office of Education.

Educational Review Office. (2005). Annual Report. Wellington: ERO.

Elliott, J. (2001) Making evidence-based practice educational? British Journal of Educational Research, 27(5), 555-574.

Evans, J., \& Benefield, P. (2001). Systematic reviews of educational research: Does the medical model fit? British Journal of Educational Research, 27(5), 527-541.

Farquhar, S. (2003). Quality teaching: Early foundations. Best evidence synthesis. Wellington: Ministry of Education.

Furlong, J. (2005). BERA at 30. Have we come of age? British Educational Research Journal, 30(3), 343-358.

Hammersley, M. (2001). On "systematic" reviews of research literature: A "narrative" response to Evans and Benefield. British Educational Research Journal, 27(5), 543-554.
Hammersley, M. (2004). Some questions about evidence-based practice in education. In G. Thomas \& R. Pring (Eds.), Evidence-based practice in education. Berkshire: Open University.

Hargreaves, D. (1996). Teaching as a research-based profession: Possibilities and prospects. London: Teacher Training Agency.

Hargreaves, D. (1997). In defence of research for evidence-based teaching: A rejoinder to Martyn Hammersley. British Educational Research Journal, 23(4), 405-420.

Hattie, J. (2005, August). What is the nature of evidence that makes a difference to learning? Keynote address to the 10th annual conference of the Australian Council for Educational Research, Melbourne.

Hodkinson, P. (2004). Research as a form of work: Expertise, community and methodological objectivity. British Educational Research Journal, $30(1), 9-26$.

Jones, A. (2005). Reflecting on the development of a new school subject: Implications for curriculum, teaching and learning. Unpublished inaugural lecture presented at the University of Waikato, Hamilton.

Lagemann, E. (1989). The plural worlds of educational research. History of Education Quarterly, 29(2), 184-214.

Lagemann, E. (2000). An elusive science: The troubling history of educational research. Chicago: University of Chicago Press.

Luke, A. (2003). After the marketplace: Evidence, social science and educational research. The Australian Educational Researcher, 30(2), 87-107.

MacLure, M. (2005). "Clarity bordering on stupidity": Where's the quality in systematic review? Journal of Educational Policy, 20(4), 393-416.

Middleton, S. (2004, November). Disciplining the subject: The impact of PBRF on education academics. Paper presented at the annual conference of the New Zealand Association for Research in Education, Wellington.

Mitchell, L., \& Cubey, P. (2003). Characteristics of professional development linked to enhanced pedagogy and children's learning in early childhood settings. Best evidence synthesis. Wellington: Ministry of Education.

Oakley, A. (2001). Making evidence-based practice educational: A rejoinder to John Elliott. British Educational Research Journal, 27(5), 575-576. 
O'Neill, O. (2002). A question of trust. Reith lectures 2002. Cambridge: Cambridge University Press.

Peile, E. (2004). Reflections from medical practice: Balancing evidence-based practice with practice-based evidence. In G. Thomas \& R. Pring (Eds.), Evidence-based practice in education (pp. 102-118). Berkshire: Open University Press.

Phillips, G., McNaughton, S., \& McDonald, S. (2001). Picking up the pace: Effective literacy interventions for accelerated progress over the transition into decile 1 schools. Final report to the Ministry of Education on PD associated with the Early Childhood Primary Links via Literacy (ECPL) project.

Pring, R. (2004). Conclusion: Evidence-based policy and practice. In G. Thomas \& R. Pring (Eds.), Evidence-based practice in education (pp. 201-212). Berkshire: Open University Press.

Slavin, R. (1986). Best-evidence synthesis: An alternative to meta-analytic and traditional reviews. Educational Researcher, 15(9), 5-11.

Slavin, R. (2003). A reader's guide to scientifically based research. Educational Leadership, 60(5), 12-16.

Stewart, D. (1980). School development: A consultative approach. Unpublished PhD thesis, Massey University, Palmerston North.

Timperley, H., \& Parr, J. (2005). Using evidence in teaching practice: Implications for professional learning. Wellington: Hodder Moa Becket.

Tooley, J., \& Darby, D. (1998). Educational research: An Ofsted critique. London: Office for Standards in Education.

Woodhead, C. (1998, March 20). Academia gone to seed. New Statesman, pp. 51-52.

\section{The author}

Noeline Alcorn is Emeritus Professor of Education at the University of Waikato where she was formerly Dean of the School of Education. She now works part time in the Wilf Malcolm Institute for Educational Research at the university. She has recently completed an evaluation of a national literacy initiative for the Ministry of Education and her current research interests include educational policy, teacher professional development and educational leadership. This article is based upon an address originally delivered as the Herbison Lecture at the NZARE conference in 2005. 